\title{
História do Português de São Paulo
}

\section{Apresentação}

Ataliba T. de Castilho (USP, Unicamp, CNPq)

Este volume da revista Filologia e Linguistica Portuguesa divulga parte da produção do Projeto de História do Português de São Paulo (PHPP), lançado em 1997 pelo Programa de Pós-graduação em Filologia e Língua Portuguesa da USP.

Com esse projeto, a Área de Filologia e Língua Portuguesa retomou a tradição uspiana dos estudos diacrônicos, deslocando, porém, os interesses da România Velha para a România Nova. Outra motivação foi buscar as raízes diacrônicas do português de São Paulo, descrito na altura por projetos coletivos, tais como o Projeto da Norma Urbana Culta (NURC, desde 1970) e o Projeto de Gramática do Português Falado no Brasil (PGPF, 1988-2002). Ambos os projetos tinham acumulado um enorme conhecimento sobre o português brasileiro. Essa variedade foi implantada em São Vicente, a partir de 1532, irradiando-se depois para São Paulo e Santana de Parnaíba, de onde se espalharia para o norte e para o sul do país. Faltava, portanto, estudar o português paulista do ponto de vista histórico.

Decidiu-se que o PHPP seguiria o mesmo ritmo do PGPF: os pesquisadores escolheriam um recorte teórico, com base no qual seriam relacionados os temas de pesquisa, a desenvolver em corpus editado filologicamente. Os resultados parciais seriam apresentados e discutidos em seminários anuais.

O I Seminário do PHPP foi realizado em 1998. Colegas de outras partes do país tinham sido especialmente convidados a participar. Ao término desse seminário, decidiu-se estender seu âmbito geográfico, surgindo assim o Projeto para a História do Português Brasileiro (PHPB). 
O PHPB realizou até à data oito seminários, todos eles com suas atas publicadas: Castilho (org. 1998), Mattos e Silva (org. 2001), Alkmim (org. 2002), Duarte / Callou (orgs. 2002), Ramos / Alckmin (orgs. 2007), Lobo / Ribeiro / Carneiro / Almeida (orgs. 2006), Aguilera (org. 2009), Hora / Rosa (orgs. 2010).

Nos últimos dez anos esse projeto passou por uma enorme expansão, com a ampliação das equipes regionais e de seus interesses científicos.

As seguintes equipes regionais constituem o PHPB, indicando-se entre parênteses o respectivo coordenador:

1. Alagoas (Maria Denilda Moura, UFAL)

2. Bahia (Rosa Virgínia Mattos e Silva, substituída a seu pedido por Tânia Lobo, UFBa)

3. Ceará (Áurea Suely Zavam, UFCe)

4. Minas Gerais (Jânia Ramos, UFMG)

5. Paraíba (Dermeval da Hora, substituído a seu pedido por Camilo Rosa, UFPb)

6. Paraná (Sônia Cyrino, substituída a seu pedido por Vanderci Aguilera, UEL)

7. Pernambuco (Marlos Barros Pessoa, substituído por Valéria Gomes, UFPe)

8. Rio de Janeiro (Dinah M. Isensee Callou, UFRJ)

9. Rio Grande do Norte (Marco Antônio Martins, UFRN)

10. Santa Catarina (Gilvan M. de Oliveira, substituído a seu pedido por Izete L. Coelho, UFSC)

11. São Paulo (Ataliba T. de Castilho, USP, substituído a seu pedido por Clélia C. Jubran, Unesp/SJRP e Manoel Mourivaldo Santiago Almeida, USP)

As seguintes áreas de atuação estruturam o PHPB, indicando-se entre parênteses os coordenadores:

1. Linguística de Corpus: Afrânio Gonçalves Barbosa (UFRJ), Marcelo Módolo (USP)

2. História social: Dinah I. Callou (UFRJ), Tânia Lobo (UFBa), Jânia Ramos (UFMG), Marilza de Oliveira (USP) 
3. Fonologia diacrônica: Dermeval da Hora (UFPb), Elisa Battisti e Valéria Monaretto.

4. Sintaxe funcionalista: Ataliba T. de Castilho (USP/Unicamp) e Célia Regina dos Santos Lopes (UFRJ)

5. Sintaxe gerativista: Sônia L. Cyrino (Unicamp) e Ilza Ribeiro (UEFS)

6. Lexicologia histórica: Vanderci Aguilera e Fabiane Cristina Altino (UEL)

7. Diacronia dos processos constitutivos do texto: Clélia C. Spinardi Jubran e Sanderléia Longhin (Unesp/São José do Rio Preto)

8. Tradições discursivas: constituição e mudança dos gêneros discursivos. Organizadoras: Maria Lúcia C.V.O. Andrade (USP) e Valéria Gomes (UFPe)

Ao longo de 2006, a equipe paulista promoveu internamente uma discussão, tendo por finalidade dar um balanço nas atividades até então promovidas e projetar os próximos movimentos. Foram realizados três seminários com essa finalidade, de que resultou a fixação dos seguintes objetivos:

1. Traçar a sócio-história do português paulista, estudando a ocupação demográfica do território, a formação das variedades culta e popular, e a difusão da variedade popular em direção a Mato Grosso.

2. Estudar a mudança gramatical da variedade paulista do Português Brasileiro, do ângulo funcionalista-cognitivista e do ângulo gerativista, com ênfase nas classes de palavras e nas construções sintáticas.

3. Investigar a diacronia dos processos constitutivos do texto e a transformação dos gêneros discursivos, como uma nova frente de trabalhos na Linguística Histórica da Língua Portuguesa.

4. Organizar e disponibilizar o Corpus diacrônico do português paulista, de forma a estimular novas pesquisas sobre essa variedade.

Cada objetivo seria considerado por projetos de pesquisa específicos, da seguinte forma:

1. História social do português paulista

1.1 Ângela C. S. Rodrigues (USP) - Retrato sociolinguístico da variedade popular na cidade de São Paulo no final do séc. XX e começo do séc. XXI. 
1.2 Marilza de Oliveira (USP) - Formação do português paulista culto e o papel das grandes escolas (1820-1934).

1.3 Maria Célia Lima-Hernandes (USP) - Retrato sociolinguístico da variedade culta paulistana falada (segunda metade do século XX a início do século XXI).

1.4 Manoel Mourivaldo Santiago Almeida (USP) - Formação e expansão do português paulista ao longo do Rio Tietê a partir do séc. XVI.

2. Mudança gramatical do português paulista

2.1 Maria Aparecida Torres-Morais (USP) - Mudança gramatical do português de São Paulo: expressão pronominal e preposicional dos argumentos.

2.2 Ataliba T. de Castilho (USP) - Mudança linguística multissistêmica do português paulista: o sistema das preposições nos séculos XIX e $\mathrm{XX}$.

2.3 Célia Maria Moraes de Castilho (pós-doutoranda, USP, bolsista da FAPESP) - Investigando a Gramática I do Português Paulista: o problema da concordância.

2.4 Verena Kewitz (pós-doutoranda, Unicamp, bolsista da FAPESP) A representação do ESPAÇO no português paulista, numa abordagem sociocognitiva.

2.5 José da Silva Simões (doutor - USP) - Sintaticização, semanticização e discursivização de estruturas hipotáticas e para-hipotáticas do Português Brasileiro.

\section{Diacronia do texto e do discurso}

3.1 Clélia Cândida Spinardi Jubran (Unesp / São José do Rio Preto) Diacronia dos processos constitutivos do texto.

3.2 Maria Lúcia C.V.O. Andrade (USP) - Tradições discursivas: constituição e mudança dos gêneros discursivos numa perspectiva diacrônica.

4. Organização do corpus diacrônico do português paulista

4.1 Marcelo Módolo - Organização e coordenação do corpus diacrônico do português paulista

Os seguintes especialistas aceitaram convite para operar como consultores do projeto: 
1. História da língua portuguesa: Prof. Dr. Ivo Castro (Universidade de Lisboa)

2. Tradições discursivas: Prof. Dr. Johannes Kabatek (Universidade de Tuebingen)

3. Linguística cognitiva: Prof. Dr. Augusto Soares da Silva (Univ. Católica de Braga)

4. Teoria gerativa da mudança: Profa. Dra. Mary A. Kato (Unicamp)

5. Teoria da variação e mudança: Profa. Dra. Maria Luiza Braga (UFRJ)

6. Dialetologia do português brasileiro: Profa. Dra. Suzana Alice M. Cardoso (UFBa)

7. Demografia histórica de São Paulo: Prof. Dr. Carlos de Almeida Prado Bacellar (USP)

O projeto foi apresentado à Fundação de Amparo à Pesquisa do Estado de São Paulo (FAPESP), que o aprovou na modalidade "projeto temático de equipe" (proc. 06/55944-0), com financiamento para o período de 2007 a 2010.

Atualmente, mais de sessenta pesquisadores integram a equipe paulista do PHPB, tendo-se realizado onze seminários para o debate de aspectos específicos da agenda:

IV Seminário do Projeto de História do Português Paulista: Linguística histórica e tradições discursivas. São Paulo / Campinas, 19 a 23 de março de 2007. Organizador: Prof. Dr. Ataliba T. de Castilho. Pesquisador convidado: Prof. Dr. Johannes Kabatek (Universidade de Tübingen, Alemanha)

V Seminário do Projeto de História do Português Paulista: Linguística histórica e demografia histórica. São Paulo, 6 de junho de 2007. Organizador e coordenador: Prof. Dr. Carlos de Almeida Prado Bacelar (Departamento de História, USP)

VI Seminário Internacional do Projeto de História do Português Paulista: Linguística histórica e Funcionalismo linguístico. São Paulo, 18 a 19 de junho de 2007. Organizadora: Profa. Dra. Maria Célia Lima Hernandes (USP). Pesquisadores convidados: Elizabeth Traugott (Stanford University), Bernd Heine (Univesitaet zu Koeln), Maria Luiza Braga (UFRJ).

VII Seminário do Projeto de História do Português Paulista: o Português de Moçambique. São Paulo, 17 a 20 de setembro de 2007. Coordenadoras: Marilza 
de Oliveira e Ângela C. S. Rodrigues. Pesquisadores convidados: Maria Perpétua Gonçalves (Universidade Eduardo Mondlane, Maputo, Moçambique) e Uli Reich (Universitaet zu Koeln).

VIII Seminário do Projeto de História do Português Paulista: Linguística histórica e gramática gerativa. Campinas, 3 a 7 de dezembro de 2007. Organizadora: Profa. Dra. Sônia Lazzarini Cyrino. Pesquisadores convidados: Prof. Dr. Ian Roberts e Profa. Dra. Mary A. Kato.

IX Seminário do Projeto de História do Português Paulista: Linguística histórica, e Linguística cognitiva. São Paulo, 6 a 10 de outubro de 2008. Organizadores: Profs. Drs. Marilza de Oliveira, Verena Kewitz, José da Silva Simões. Pesquisador convidado: Prof. Dr. Augusto Soares da Silva (Universidade Católica Portuguesa, Braga).

X Seminário do Projeto de História do Português Paulista: as vésperas brasilianas. São Paulo, 3 a 7 de agosto de 2009. Organizador: Prof. Dr. Ataliba T. de Castilho. Pesquisador convidado: Prof. Dr. Ivo Castro (Universidade de Lisboa).

XI Seminário do Projeto de História do Português Paulista: o português em tempos de Cabral. São Paulo, 3 a 7 de agosto de 2009. Organizador: Prof. Dr. Ataliba T. de Castilho. Pesquisadora convidada: Profa. Dra. Clarinda Maia (Universidade de Coimbra).

Foi convocado para abril de 2011 o XII Seminário, em que serão discutidas as atividades desenvolvidas de 2007 a 2010, bem como a definição da continuidade dos trabalhos, dando-se posse aos novos coordenadores, Profs. Drs. Clélia C. S. Jubran e Manoel Mourivaldo Santiago Almeida.

Para publicar a produção do grupo, foi lançada a obra História do Português Paulista, com duas séries: uma série de estudos e uma série de corpora. $\mathrm{Na}$ série de estudos foram publicados até a data dois volumes, estando um terceiro no prelo: Castilho (org. 2009), Torres Morais / Andrade (orgs. 2009), LimaHernandes / Santiago-Almeida (orgs. no prelo), Módolo / Simões / Kewitz (orgs., no prelo). Na série de corpora, está no prelo e aí segue com o que esta: Módolo / Simões / Kewitz (orgs., no prelo).

Neste número temático da revista Filologia e Linguística Portuguesa são publicados os seguintes textos:

Maria Lúcia da Cunha Victorio de Oliveira Andrade / Fabio Fernando Lima / Kelly Cristina de Oliveira / Paulo Roberto Gonçalves Segundo / Rafaela Baracat Ribeiro - Novos caminhos da Linguística textual. Discute-se aqui o con- 
ceito de tradições discursivas, apresentando-se parte das pesquisas que vêm sendo desenvolvidas pelos integrantes do PHPP dentro do subprojeto "Tradições discursivas: constituição e mudança dos gêneros numa perspectiva diacrônica".

Henrique Santos Braga - Mudança linguística no modo imperativo. Uma análise multissistêmica. A partir de um corpus composto por textos dramáticos, produzidos no sudeste brasileiro entre 1850 e 1975, esta pesquisa se destina a estudar o uso que os falantes fizeram, ao longo desse período, das formas do singular do modo imperativo. O objetivo do trabalho é investigar usos de épocas passadas, visando a identificar se, ao longo do tempo, além da variação, é possível ainda observar um processo de mudança linguística envolvendo essas formas verbais. Para tratar do fenômeno em questão, optou-se pela Teoria multissistêmica ( $f$. Castilho, 2006) e ainda por sugestões metodológicas da sociolinguística variacionista para quantificar os dados em análise.

Ataliba T. de Castilho - Representaçẽes das categorias cognitivas e sua diacronia. A interface Linguística cognitiva - Linguística histórica. A partir dos anos 80 do século passado, a Linguística histórica voltou a ocupar a atenção dos linguistas brasileiros. O objetivo deste trabalho é identificar novos rumos na pesquisa diacrônica. O texto em três secções: momentos da Linguística histórica, sistemas complexos e Linguística histórica, representação da categoria de MOVimento na história da língua portuguesa. Nas conclusões, propõe-se que o Princípio de projeção reúne todas as manifestações linguísticas de MOVIMENTO.

Verena Kewitz - A representação do MOVIMENTO no português paulista. $\mathrm{O}$ trabalho analisa de que maneira o MOVIMENTO pode ser organizado e representado no Português Paulista em corpora dos séculos XVIII a XX. Para tanto, são analisados os padrões de combinação propostos por Talmy (2000b) e a representação dos pontos do percurso num deslocamento no espaço físico. A análise é qualitativa e quantitativa, e nesse caso, foram tomadas em conta as propriedades discursivas dos textos que compõem os corpora, à luz do modelo de Tradições discursivas.

Celso Massato Kobashi - Sintaticização e discursivização das construções condicionais no português popular falado na cidade de São Paulo. Este trabalho trata dos processos de semanticização e discursivização das construções condicionais no português popular falado na cidade de São Paulo. Tendo como base a Abordagem Multissistêmica da Lingua (Castilho, 2010) e a Linguística Funcional, 
realiza-se aqui uma análise qualitativa, abordando os principais aspectos semânticos (condicionais reais, irreais e eventuais; implicativas, epistêmicas, entre outras nuances) e discursivos pertinentes às construções hipotéticas.

Sanderléia Roberta Longhin-Thomazi - Flutuação e gramaticalização no paradigma dos juntores em português: forma, significado e história de (na) hora que. Focaliza-se neste trabalho um tipo de mudança gramatical que consiste na criação de juntores perifrásticos a partir de fontes nominais usadas em contextos de oração relativa. Trata-se de um mecanismo de produção de perífrases que vem ampliando o instável paradigma dos juntores e ajudando a delinear a gramática do português. Uma construção resultante desse mecanismo é (na) hora que, sobre a qual se investiga a forma, o significado e a história. A questão central é mostrar que a emergência de (na) hora que é uma instância de gramaticalização em curso, em que é possível flagrar etapas do processo gradual de sua constituição, tanto no que se refere à reorganização sintagmática dos itens, com consequente perdas morfológicas, como também no que se refere à constituição dos sentidos, com o surgimento de polissemias, que apontam para uma direcionalidade fundada no aumento de complexidade cognitiva.

Lúcia R. Lopes Damasio - "Assim, como estas, muitas outras questões interessantes e de actualidade ficarão pairando na dúvida": uma análise de assim como no dominio da junção. A partir de Halliday (1985) e Raible (1992, 2001), o trabalho propõe que os padrões interproposicionais de assim distribuem-se em um continuum, configurado entre os usos representativos dos diferentes tipos de interdependência, partindo dos exemplares de relações do domínio da parataxe até os exemplares de relações hipotáticas, passando pelos que estão entre um e outro pólo do continuum. O trabalho é ilustrado a partir do funcionamento da locução assim como, numa descrição de seu comportamento sintático-semântico no corpus selecionado e numa análise das evidências do processo de mudança linguística, via gramaticalização, que subjaz seu funcionamento como juntor, a fim de apontar o lugar, no continuum, ocupado por esse padrão.

Deize Crispim Pereira / Ângela C.S. Rodrigues - Todos são x tudo é: os usos do pronome tudo no português popular falado em São Paulo. Este trabalho analisa quantitativamente os pronomes tudo/todos em contextos nos quais estes retomam ou se combinam com um nome ou pronome semanticamente ou sintaticamente plural. O corpus se constitui de 34 inquéritos que integram o Projeto Português Popular em São Paulo. Utilizando os pressupostos teórico-metodológicos da Sociolinguística variacionista laboviana e da Linguística funcional, 
são descritas as condições de uso destes pronomes e analisados os fatores que condicionam a variação entre realização x não da flexão do pronome e da flexão do verbo.

Manoel Mourivaldo Santiago-Almeida / Manoella Neres Jubilato / Cátia Schreiner - Sobras e sombras nobres e plebeias do século ХVI. Tendo como base o livro Ditos portugueses dignos de memória (1997), elaborado a partir da tradição oral do português quinhentista ( $=$ registros de fala extraídos do cotidiano da nobreza à plebe), este texto destaca lexias e expressões consideradas fora de uso no atual português europeu, e que, em contrapartida, são do uso corrente no português brasileiro de hoje.

Célia Maria Moraes de Castilho - Os inventários e testamentos como documentos linguísticos. O objetivo deste artigo é apresentar uma categorização sóciohistórica dos autores dos Inventários e Testamentos, escritos em São Paulo nos séc. XVI e XVII. Juntamente com as Atas da Câmara da Vila de São Paulo, são estes os documentos públicos mais antigos da cidade. Para atingir esse objetivo, o trabalho foi dividido em três partes: (i) notas para a história social de São Paulo em seus primeiros séculos, (ii) o português médio e o protocaipira, (iii) Inventários e Testamentos como documentos linguísticos. Os escrivães portugueses, paulistanos e parnaibanos, autores desses documentos, além de alguns estrangeiros, são enumerados no Anexo, objetivando facilitar sua utilização pelos pesquisadores. Nas Conclusões, estuda-se a distribuição percentual dos autores de Inventários e Testamentos de acordo com sua origem, avançando algumas hipóteses sobre a mudança linguística do Português Paulista com base nesses dados.

\section{Referências bibliográficas}

AGUILERA, Vanderci de Andrade (Org., 2009). Para a História do Português Brasileiro, vol. VII: vozes, veredas, voragens, 2 tomos. Londrina: Editora da Universidade Estadual de Londrina.

ALKMIM, Tânia (Org., 2002). Para a História do Português Brasileiro, vol. III, Novos Estudos. São Paulo: Humanitas / Unicamp - USP.

CASTILHO, Ataliba T. (Org., 1998). Para a História do Português Brasileiro, vol. I, Primeiras ideias. São Paulo: Humanitas / Fapesp.

CASTILHO, Ataliba T. (Org., 2009). História do Português Paulista. Série Estudos, vol. 1. Campinas: Fapesp / Setor de Publicações do Instituto de Estudos da Linguagem da Unicamp.

DUARTE, Maria Eugênia Lamoglia / CALLOU, Dinah M. Isensee (Orgs., 2002). Para a História do Português Brasileiro, vol. IV, Notícias de corpora e outros estudos. Rio de Janeiro: UFRJ Letras / Faperj. 
HORA, Dermeval / ROSA, Camilo (orgs. 2010). Para a História do Português Brasileiro, vol. VIII. João Pessoa: Universidade Federal da Paraíba.

LIMA-HERNANDES, Maria Célia / SANTIAGO-ALMEIDA, Manoel Mourivaldo (Orgs., no prelo). História do Português Paulista, série Estudos, vol. 3.

LOBO, Tânia C. F. / RIBEIRO, Ilza / CARNEIRO, Zenaide / ALMEIDA, Norma (Orgs., 2006). Para a História do Português Brasileiro, vol. VI: Novos dados, novas análises, 2 tomos. Salvador: Editora da Universidade Federal da Bahia.

MATTOS E SILVA, Rosa Virgínia (Org. 2001). Para a História do Português Brasileiro, vol. II, Primeiros Estudos, 2 tomos. São Paulo: Humanitas / Fapesp.

MÓDOLO, Marcelo / SIMÕES, José da Silva / KEWITZ, Verena (Orgs., no prelo). História do Português Paulista. Série Corpus, vol. 1. Campinas: Fapesp / Setor de Publicações do Instituto de Estudos da Linguagem da Unicamp.

RAMOS, Jânia / ALCKMIN, Mônica A. (Orgs. 2007). Para a História do Português Brasileiro, vol. V: Estudos sobre mudança linguística e história social. Belo Horizonte: Faculdade de Letras da Universidade Federal de Minas Gerais.

TORRES MORAIS, Maria Aparecida C.R. / ANDRADE, Maria Lúcia C.V.O. (Orgs., 2009). História do Português Paulista. Série Estudos, vol. 2. Campinas: Fapesp / Setor de Publicações do Instituto de Estudos da Linguagem da Unicamp. 